Teaching \& Learning (2013) 7(3), 47-61

\title{
"Membership Has Its Privileges": The Elusive and Influential Nature of Special Education Expertise
}

\author{
CAM COBB \\ University of Windsor
}

\begin{abstract}
Special education is brimming with individuals who are often called experts. Speech-language pathologists, consultants, psychologists and a host of others are all, in varying contexts, considered to be experts. But are parents also not experts? And what exactly is an expert? These are all important questions. If perspectives of expertise influence the way in which voices are heard in special education processes, then questions about expert identity and the purported objectivity of expert knowledge and language are ones we need to ponder. In this discussion paper, I draw from two composite narratives - fictionalized accounts of my own experiences - to identify aspects of special education knowledge and language expertise, and consider how they might influence parental inclusion. Given the effects of various forms of expertise in special education, we ought to encourage a form of reciprocity that facilitates parental inclusion. Questions are posed throughout the paper to highlight not only the importance of inclusion and reciprocity, but also ways in which they might be fostered.
\end{abstract}

\section{Introduction}

Desmond Widmore, the lead special education teacher at Bentham Elementary, had a busy Monday. He attended a hurried meeting with the vice-principal (VP) before the morning bell. The VP outlined changes to school board policy, regarding the way in which behaviour logs were to be developed and kept. It was expected that Desmond would then relay this information, and support teachers, as they adjusted their method of tracking and supporting the behavioural needs of a small number of children at the school. Following the morning announcements, Desmond had a telephone conversation with a Speech-language pathologist (SLP), who explained why, in her view, a child in Grade 1 was not in need of individualized support. During morning recess, Desmond fleetingly conferred with a school board psychologist on the progress of two assessments that were nearing completion.

After lunch, Desmond chatted with a visiting special education coordinator about the learning profile of a child with special needs, who had transferred to the school the previous week. For the rest of the afternoon he conversed with parents and school professionals in a 
"Membership Has Its Privileges"

flurry of meetings. The purpose of these meetings was to discuss the possibility of developing Individual Education Plans (IEP) for nine children who had been struggling at the school. An IEP sets out specific classroom supports (in the form of accommodations), and, in some cases, also indicates how a child's curricular expectations differ from her/his grade level expectations (in the form of modifications). In Desmond's afternoon meetings, it was ultimately decided that seven of the nine children qualified for an IEP.

The preceding vignette depicts a busy Monday as experienced by Desmond Widmore. As the day unfolded, he interacted with numerous individuals who are commonly viewed as experts. He conferred with these individuals for a variety of reasons, and each one of them exerted an influence on special education decision-making in a different way. While this narrative is fictional, it draws from my own personal history. In presenting two composite narratives in this paper, I aim to evocatively summarize interconnected experiences I have had in the special education milieu (Hoogland \& Wiebe, 2012). This first vignette highlights the influential nature of expertise in special education. But what is expertise? And how is it attributed to individuals?

\section{What Is Expertise?}

Collins and Evans (2002) outline two common ways of conceptualizing and attributing expertise to individuals in society. First, demonstrating a high degree of knowledge and/or skills in a certain area is often believed to be an indicator of expertise. Second, formal recognition (i.e., certification), as well as experience are also, at times, perceived as being tangible evidence of expertise. With these models in mind, it is possible to take two approaches to identifying expert educators. First, many educators spend years demonstrating knowledge and skills in the area of teaching and learning. Some have drawn from this qualitative-oriented view to detail what would make a teacher an expert in a particular area of education. According to Ebmeier, Beutel, and Dugan (2010), for instance, foundational skills and attributes of special education teacher-experts include "the ability to assess student behavior, attention levels and state of mind; knowledge and use of instructional strategies, classroom-wide behavioural management and individualized behavioral strategies; and a strong focus on academic, behavioural and emotional outcomes for students with disabilities" (p. 88). Second, the field of education is replete with multiple and varied opportunities for certification. After obtaining a Bachelor of Education degree and teaching certificate, for instance, educators in Ontario, might choose from an array of Additional 
Basic Qualification (ABQ) and Additional Qualification (AQ) courses to pursue supplementary certification and, in some circumstances, specialist status (i.e., special education specialist). Ontario Teaching Certificates, as well as ABQ and AQ courses, are regulated by the Ontario College of Teachers.

But how accurate are these models? While the two above-mentioned approaches to conceptualizing and identifying expertise can be informative (Collins \& Evans, 2002), the practice of assigning expert authority to individuals is unstable. In conducting a concept analysis of the term, Jasper (1994) concluded that: "The attribution of expertise remains linked to subjective criteria and reputation, with all of the defining attributes (knowledge, expertise, pattern recognition, and recognition by others) having loosely defined parameters" (p. 775). This possibility of loose parameters raises an important question: If expertise is in actuality a matter of subjective judgement, then what exactly would make someone a special education expert?

Related questions also deserve our attention. If fluency in special education knowledge and language represents a sort of privileged membership in the expert domain, then what would the privileges be of this membership? Further, if only the voices of experts are privileged in shared decision-making processes, what does this mean for parental inclusion? What are the wider implications of such a dynamic? In this paper, I consider how perceptions of expert knowledge and language might influence parental inclusion in special education. We might define parental inclusion as the practice of seeking out, dialoguing with, and drawing from parental contributions, when engaging in decision-making processes (Ryan, 2010). My aim in this paper is to indicate that, given the effects of various forms of expertise in special education, we ought to encourage a form of reciprocity that facilitates parental inclusion.

To explore the relationship between special education expertise and parental inclusion, I have organized this paper into four segments: (1) Social-Cultural Capital, (2) Objectivity, (3) Knowledge Expertise, and (4) Language Expertise. Throughout the paper, I pose critical questions, which, in a holistic sense, ask: What can be done to foster reciprocity? To address these questions I draw from government documents, current research, and my own experience in the field.

\section{Social-Cultural Capital}

While working for a large urban Ontario school board, I spent over a decade teaching at two elementary schools. In one school, I worked as a lead special education teacher and 
facilitated the development of over 70 IEPs, and contributed to over 70 Identification, Placement, and Review Committee (IPRC) meetings. In Ontario, IPRC meetings are held to determine if a child's learning profile qualifies her/him to be formally identified as having an exceptionality, and decide how the needs of that child would best be served (i.e., placement) (Ontario Ministry of Education, 2001). Over the years I have had a variety of opportunities to experience, observe, and learn about challenges in special education. Some of the challenges I have noticed relate to the barriers parents face as they endeavour to take part in decision-making processes.

Social-cultural capital provides a useful way of understanding parental inclusion. But what exactly is social-cultural capital? Most generally, it is a metaphor. In our day-to-day activities, we interact with friends, associates, and family members in a variety of contexts and manners, and, at times, these interactions foster situations of privilege (Bourdieu, 1985). Our social relations lead us to draw from the capital of associates, which themselves have varying quantities and perceived qualities in the larger social milieu (Portes, 1998). As a consequence, one's familiarity, fluency, and/or comfort with a school's routines - such as its modes and manners of communication - will, at times, put some parents at an advantage and others at a disadvantage, when they seek to contribute to decision-making processes. For instance, the way in which a parent engages in small talk, expresses her/his views, and negotiates with school professionals will, in part, be influenced by that parent's social-cultural capital. The voices of parents who utilize social-cultural capital that is highly valued by school professionals are more likely to be heard in parent-school interactions (Reay, 1998; Hornby \& Lafaele, 2011). Lai and Ishiyama (2004) identified consequences of this phenomenon when examining the involvement of Chinese-Canadian immigrant mothers of children with disabilities. According to the researchers, value divergence and communication issues were two key reasons why the "mothers were not very involved in the school, which was in stark contrast to their desire to help their children learn and develop, to their involvement in home teaching, and to the high value they placed on education" (p. 105). These capital-oriented barriers have wider social implications, because parental inclusion itself is "central to a democratic school system" (Philpott, Furey, \& Penney, 2010, p. 41).

Utilizing the lens of social-cultural capital to understand parental inclusion is not a matter of questioning whether or not a given parent possesses any capital, but rather a matter of investigating which sorts of capital habitually get privileged. In considering special education, 
we might say that one's acceptance, awareness, and strategic use of special education-oriented knowledge (i.e., concepts) and language (i.e., terminology) constitute two interrelated sources of social-cultural capital that are commonly privileged (Cobb, 2012a). When participating in special education processes, a parent's access to, and interpretation of, knowledge and language can profoundly influence the ways in which s/he is perceived and treated by others (Cobb, 2012a; Harry, 2008; Trainor, 2010ab). In sum, one's access to social-cultural capital that is valued by a system could be described as a sort of club membership, and, as a successful American Express advertising campaign once articulated: "Membership has its privileges" (Fisher, 1991).

\section{Objectivity}

While social-cultural capital, as a lens, can help us recognize dimensions of privilege in special education, it is also necessary to consider whether or not the process of assigning expert value to something, is actually objective. Before I discuss the matter of objectivity in special education, however, it is necessary to consider objectivity in a more general sense. Throughout history people have debated over the possibility of objective truth. Does such a thing exist? And if it does, is it knowable? Realists, like Plato and Aquinas, argued that pure truths do exist, but lurk outside the physical world (Kneller, 1971). Conversely, a number of thinkers have applied the critical approaches of scepticism (Landesman \& Meeks, 2003), discourse analysis (Foucault, 1984), and anti-realism (Dummett, 1978), to raise questions about the possibility of pure truths, as well as knowable truths. Those who hold a postmodern view - which in part draws from the three above-listed critical approaches - have a "friendly suspicion that all truth claims are suspect and provisional, at best" (Lincoln, 2010, p. 4). But how does this debate about objective truth link to special education expertise?

Special education is comprised of a variety of ideas and practices, which are rooted in certain pools of knowledge and language. These ideas and practices can be found in codified definitions (such as the definitions of different exceptionalities), and habits (such as modes and procedures of assessment). Some believe that the ideas and practices of special education should be rooted in scientific empiricism, and draw from objective truths (Kauffman \& Sasso, 2006; Kavale \& Mostert, 2003). A number of those who hold this view infer that experts are able to apply their knowledge and language to equivocally define, and then accurately measure such 
things as a child's intelligence, motivation, emotional needs, and memory capacity (Reid \& Valle, 2004).

But not everyone holds this view. Some counter that attempting to define and then measure such things as ability is a highly elusive business (Mellard, Deshler, \& Barth, 2004; Reid \& Valle, 2004). Reid and Valle (2004), for instance, have pointed out that exceptionalities, such as learning disabilities (LD), are "historically and culturally determined" (p. 466). But if exceptionalities are fluid, how could they be perceived as being pure and knowable truths? Of course, this debate over truth and objectivity is ongoing. Kaufman and Sasso (2006) tersely announced, "arguments about doubt, certainty, and objectivity are both old and unsound ... Implications of cultural and cognitive relativism for special education are severe and negative" (p. 109). Ultimately, one's views of objectivity and truth influences how one perceives learning, which in turn shapes how one defines strengths and needs, and engages in dialogue about such matters. Consequently, it is impossible to disentangle questions about objectivity from questions about special education expertise.

\section{Are Assessments Objective?}

As you read over the following vignette, reflect on these three questions: (1) What knowledge is perceived as being objectively true in the scenario? (2) How is this knowledge viewed by different people? (3) What sorts of things influenced parental inclusion in the vignette?

Desmond Widmore had a stack of IEPs to edit and was midway through the first when his intercom phone rang out. It was Ben Gale, a colleague. Ben taught the Mild Intellectual Disability (MID) class for junior-aged (Gr. 4-6) learners at Bentham Elementary. In Ontario, MID classes are geared to learners who have "an inability to profit educationally within a regular class because of slow intellectual development" (Ontario Ministry of Education, 2001, p. A20).

Last month, Claire de Ravin moved to Bentham Elementary from another school board. Because she had been in an MID classroom at her previous school, she was immediately placed in Ben's class. But Claire's performance prompted Ben to inspect her Ontario Student Record (OSR), which had recently arrived at the school. In examining Claire's OSR, Ben noticed a number of contradictions. He asked Desmond to have a look at the file when he got a chance. 
"Membership Has Its Privileges"

In reading through Claire's student records, Desmond noted that the original IPRC document, dated two years earlier, designated Claire as having an MID. This was not a surprise. However, when Desmond pulled out Claire's psychological assessment (sometimes referred to as psycho-educational assessment), which had been completed three months prior to the IPRC, he was shocked to read that it recommended a Communication LD identification. In Ontario, students with Communication LDs have "a learning disorder evident in both academic and social situations that involves one or more of the processes necessary for the proper use of spoken language or the symbols of communication" (Ontario Ministry of Education, 2001, p. A19).

Later that week, Desmond met with Juliet Mitchell, the school Psychologist, and together, the two looked over Claire's OSR.

"The IPRC went against the psych report," Juliet concluded. "It happens from time to time."

"But there must have been a psychologist at the IPRC."

"Of course there was. But the IPRC committee must have disagreed with the recommendations of the psych report."

"So where do we go from here?” Desmond asked.

"We need to add Claire to my waiting list. She needs another assessment."

When John met with Claire's parents the following week, he learned that the couple was not aware of the complication. They had been told that they did not need to attend the IPRC meeting and had assumed that the IPRC would follow the recommendation of the psychological assessment.

This fictional vignette - another composite narrative - is again based on my own lived experiences as an educator. Three individuals in the narrative perceived Claire's psychological assessment as being objectively true. Desmond, for instance, was shocked to discover that one school board psychologist would counter the recommendation of another in an IPRC meeting. Like Desmond, Claire's parents believed that the psychological assessment findings were accurate, and would be treated as such at the IPRC meeting. Interestingly, it was Juliette, the school board psychologist, who was not surprised by the situation. Perhaps she was not surprised because she herself had perceived and treated the findings of psychological assessments as inaccurate information in the past. 
A number of factors influenced the inclusion of Claire's parents in this scenario. Rather than seeking out the contributions of the parents, they were dissuaded from attending an IPRC meeting on the grounds that it was a matter of formality. Following the meeting itself, no one contacted the couple to inform them that the IPRC recommendations shifted from those of the psychological assessment. The vignette provides an example of how perceived experts might have differing, and even conflicting, views on a child's learning needs. It also illustrates how parental inclusion might be compromised when they encounter information that is considered to be definitive.

\section{Knowledge Expertise}

Before I outline a few aspects of special education knowledge in Ontario, it is important for us to ponder the following questions: (1) What counts as special education knowledge? (2) Who is empowered to interpret and/or use this knowledge? (3) What happens when individuals interpret this knowledge in different ways?

\section{Malleable Knowledge}

In Canada, a combination of federal, provincial, and territorial legislation - as well as policies, regulations, and memoranda - set out the ways in which learning and behavioural needs are conceptualized and assessed (Phillips, 2010). In most cases, provincial or territorial governments outline the parameters of publicly funded special education services and procedures across the country. Because Canada's First Nations communities have retained education as a treaty right, special education services and parameters in publically funded schools on reserves fall under the jurisdiction of the federal government (Phillips, 2010). In a holistic sense, we might say that the knowledge base (i.e., ideas and assumptions) that underpins special education language (i.e., definitions), procedures, and services across Canada, is articulated by lawmakers and policymakers. But this knowledge base is ever-changing. The malleable nature of special education knowledge in Canada can be seen in situations where exceptionalities and associated services are reconstructed. For instance, definitions and funding structures around different exceptionalities shift across jurisdictional borders and time (Kozey \& Siegel, 2008). 


\section{Knowledge and Assessment}

Because special education aims to identify and support individual needs, its knowledge base rests heavily on the ways in which learning needs are assessed. Key methods of assessment for the purposes of education include: (1) continuous classroom assessment, (2) psychological assessment, (3) language assessment, (4) social/family history, and (5) assessment of observed behaviours in a variety of settings (Ontario Ministry of Education, 1982). But are these methods of assessment given comparative credence? It is important to ponder this question because there will be times when the findings of one assessment diverge from the findings of another.

In Ontario, the parameters of special education assessment are predominantly set out by Regulation 181/98 as well as Policy/Program Memorandum No. 8 (Ontario Ministry of Education, 1982; 2001). While these two documents indicate that psychological assessments are not required for a child to be formally identified as being exceptional, the assessments carry much weight. This weight can be seen in how the province spends its money. In June 2006, through the Student Assessment Project, Ontario's Ministry of Education provided the Ontario Psychological Association (OPA) with "a grant of \$20 million to be used to support school boards to reduce current wait times for students requiring professional assessments" (OPA, 2008, p. 5). Deemed to be a success (Ontario Ministry of Education, 2009), it was announced in the spring of 2008 that the project would be extended to August 31, 2009, with additional funding (OPA, 2008). But, as the previous vignette indicated, sometimes even school Psychologists can not agree on the accuracy of these assessments.

\section{Questions about Knowledge Expertise}

If perceptions of knowledge expertise represent a core aspect of special education assessment, then it is necessary to consider how these perceptions might shape interactions between parents and school professionals. We might begin by asking: What do parents need to know before they can make informed decisions about choosing - and/or discussing the results of - different sorts of assessments? This question is important because parents are not always informed about assessment details, choices, or results (Cobb, 2012a). But what happens when parents are informed of these things, and one school professional recommends one type of assessment (or interpretation of one), and the parent endorses another? In what sorts of circumstances might parents feel pressured to support a certain recommendation? The way in 
which different forms of social-cultural capital get valued can, in some circumstances, diminish the input of parents in situations of diverging perspectives (see, for example, Cobb, 2012a; Garcia, Méndez Peréz, \& Ortiz, 2000; Harry, 2008; Lai \& Ishiyama, 2004; Trainor, 2010ab).

After an assessment has been conducted, and parents seek to contribute to the discussion of its results (i.e., at an IPRC meeting), how is their input valued? Further, how is it communicated that their input is valued? Both of these questions are important because in addition to actively valuing the contributions of parents, it is necessary to clearly communicate this value. One might also ask: How are parents' views, and/or interpretations, of special education knowledge not recognized and valued? In what ways might parents be made to feel that their contributions, and/or views, are not being valued? Additionally, in what sorts of circumstances might the voices of parents be diminished, or even silenced, as they attempt to dialogue with recognized experts? While the answers to the three preceding questions would depend on contextual factors, the process of addressing them is crucial. Addressing the questions could help school professionals to identify situations where perceptions of knowledge hinder parental inclusion in special education. Reflecting on all of these questions could help guide school professionals as they seek to identify knowledge-oriented barriers, and actively work to remove them.

\section{Language Expertise}

Before we consider aspects of special education language expertise, it is necessary to reflect on the following three questions: (1) What is the language of special education? (2) Who is empowered to define and/or use this language? (3) What happens when individuals interpret this language in different ways?

\section{Terminology}

Exceptionality and identification are important words in Ontario's special education lexicon. To determine whether or not a child formally qualifies for special education support, children must be identified with an exceptionality, or combination of exceptionalities. Some of these exceptionalities include: giftedness, LD, and MID (Ontario Ministry of Education, 2001). While those who are not identified might informally access special education support, they could potentially lose that support at any time. Specifically, they could lose it if the school were to 
have an influx of exceptional learners, or if the child were to transfer to another school, or school board (Ontario Ministry of Education, 2001). If formal identification is an integral aspect of accessing special education support in Ontario, the terminology - or language-oriented expertise - associated with this process is important to understand.

In Ontario's identification process, families navigate a path that includes several stages. Early on in this journey, concerns about a child's learning are discussed by school professionals, and possibly parents, at various meetings. Sometimes these meetings are referred to as School Support Team Meetings. After the development and implementation of an IEP the child might then take part in further assessments, such as psychological assessments. Eventually, the child's needs would be discussed at an IPRC, where s/he could then be formally identified as an exceptional learner (Ontario Ministry of Education, 2001). Along this path, parents might encounter a variety of abstract and/or technical terms rooted in different discourses, such as psychology. While any individual might face challenges with special education language, I will focus on the perspective and positioning of parents in posing questions about language expertise.

\section{Questions about Language Expertise}

When perusing a psychological report, a parent might read about mnemonic devices, rote auditory information, and receptive language. Parents might also hear these terms used in telephone conversations, and/or more formal meetings. But what happens when parents encounter terms they do not understand (such as the ones listed above)? Is it possible that the pace of a meeting could actually dissuade parents from asking for clarifications? If parents are told that they will have a limited amount of time for a meeting before it commences, will they be less likely to voice their views and/or concerns at that meeting? Could the total amount of time set aside for a meeting influence a parent's likelihood of putting forward suggestions, and/or posing questions? What about the order of speakers? What happens when a parent is scheduled to be the final speaker at a meeting, and the meeting then runs over its allotted time limit? The preceding six questions are important ones to ponder because the duration, speed, and tone of special education meetings can influence the depth of dialogue between parents and school professionals, and, at times, these factors can erode parental inclusion (see, for example, Butera, 2005; Harry, 2008). 
"Membership Has Its Privileges"

We might also consider spoken language. What happens when parents who speak English as an additional language are not made aware of interpretation or advocacy supports that are available to them? How do parents in such situations navigate the terrain of special education terminology and language expertise? Limiting interpretation services - and/or neglecting to make parents aware of such services - can, as we might expect, hinder parental inclusion (see, for example, Cobb, 2012a; Lai \& Ishiyama, 2004). Critically reflecting on these languageoriented questions could guide school professionals, as they seek to identify barriers that parents might face. After identifying barriers that are rooted in special education language, strategies could be devised to actively remove them, and support parental inclusion.

\section{Conclusion}

Special education is brimming with individuals who are often called experts, and parents interact with these individuals on a regular basis. On occasion, parents themselves are considered to be experts: "Not only are parents their children's first and most important teachers, they are also experts in their children's lives, with stories to share that can shed light on the science of child development and its implementation within our local communities" (Worcester, Nesman, Raffaele Mendez, \& Keller, 2008, p. 509-510). If the skills and knowledge that parents offer are not utilized, then we might ask: Why is this so? Perhaps it is because parents are not commonly recognized as being experts.

But why is special education expertise so influential? According to Chafetz (1996), "we as a society have given [experts] more power over our lives and our thoughts, because we want what they profess to give us: definitive answers for the troubling questions in life" (p. xvii). Perhaps there are so many individuals recognized as experts in special education because the field wrestles with so many troubling questions. What is intelligence? What is memory? What is motivation? What is ability? These are difficult questions indeed. And it would be comforting to believe that there are definitive and attainable answers to these questions.

Reflecting on how expertise is conceptualized and positioned in the special education milieu is important for everyone. One reason it is important is because, at times, expertise can diminish, or even silence, the voices of parents (Cobb, 2012a). This sort of exclusion might arise in such contexts as informal telephone conversations, meetings, and written correspondences. If membership in the club of expertise has its privileges, then it is time to ask: What are the 
implications? When school professionals look out for, and actively work to remove barriers that are associated with special education expertise, they have a greater chance of fostering reciprocity and parental inclusion.

Cam Cobb joined the University of Windsor's Faculty of Education in 2010. He teaches courses on such topics as Differentiated Learning, Contemporary Issues in Education, and Curriculum Theory. Recently published papers have appeared in the British Journal of Special Education and the Canadian Action Research Journal. Cam's research interests include parental involvement, social justice, and special education.

\section{References}

Bourdieu, P. (1985). The forms of capital. In J. G. Richardson (Ed.), Handbook of theory and research for the sociology of education (pp. 241-258). New York, NY: Greenwood.

Butera, G. (2005). Collaboration in the context of Appalachia: The case of Cassie. Journal of Special Education, 39(2), 106-116.

Chafetz, M. E. (1996). The tyranny of experts: Blowing the whistle on the cult of expertise. New York, NY: Madison Books.

Cobb, C. (2012a). Speed bumps, roadblocks and tollbooths: How culturally and linguistically diverse parents navigate the highways and byways of giftedness in Ontario. British Journal of Special Education, 39(1), 12-20.

Cobb, C. (2012b). Throwing out the culturally unresponsive cookie cutter: Collaborations, concessions and curricula in a Ramadan music accommodation. Canadian Journal of Action Research, 13(3), 3-13

Collins, H. M., \& Evans, R. (2002). The third wave of science studies: Studies of expertise and experience. Social Studies of Science, 32(2), 235-296.

Dummett, M. (1978). Truth and other enigmas. Cambridge, MA: Harvard University Press.

Ebmeier, H., Beutel, J. L., \& Dugan, E. (2010). An employment interview instrument for special education teachers. Journal of Special Education Leadership, 23(2), 84-99.

Fisher, R. J. (1991). Durable differentiation strategies for services. The Journal of Services Marketing, 5(1), 19-28.

Foucault, M. (1984). Truth and power. In P. Rabinow (Ed.), The Foucault reader (pp. 51-75). New York, NY: Pantheon Books.

Garcia, S. B., Méndez Pérez, A., \& Ortiz, A. A. (2000). Interpreting Mexican-American mothers' beliefs about language disabilities from a sociocultural perspective. Remedial and Special Education, 21(2), 90-102.

Harry, B. (2008). Collaboration with culturally and linguistically diverse families: Ideal versus reality. Exceptional Children, 74(3), 372-388.

Hoogland, C., \& Wiebe, N. (2012). But she had to start with her own story: Finding aesthetic distance through a fictional character in a poetic narrative inquiry. In S. Thomas, A. L. Cole, \& S. Stewart (Eds.), The art of poetic inquiry (pp. 314-332). Toronto, ON: Backalong Books.

Hornby, G., \& Lafaele, R. (2011). Barriers to parental involvement in education: An explanatory model. Educational Review, 63(1), 37-52. 
Jasper, M. A. (1994). Expert: A discussion of the implications of the concept as used in nursing. Journal of Advanced Nursing, 20, 769-776.

Kauffman, J. M., \& Sasso, G. M. (2006). Rejoinder: Certainty, doubt, and the reduction of uncertainty. Exceptionality, 14(2), 109-120.

Kavale, K. A., \& Mostert, M. P. (2003). River of ideology, islands of evidence. Exceptionality, 11(4), 191-208.

Kneller, G. F. (1971). Introduction to the philosophy of education ( $2^{\text {nd }}$ ed.). Toronto, ON: John Wiley \& Sons, Inc.

Kozey, M., \& Siegel, L. S. (2008). Definitions of learning disabilities in Canadian provinces and territories. Canadian Psychology, 49(2), 162-171.

Lai, Y., \& Ishiyama, F. I. (2004). Involvement of immigrant Chinese Canadian mothers of children with disabilities. Exceptional Children, 71(1), 97-108.

Landesman, C., \& Meeks, R. (Eds.). (2003). Philosophical scepticism. Malden, MA: Blackwell Publishers Ltd.

Lincoln, Y. S. (2010). "What a long, strange trip it's been...": Twenty-five years of qualitative and new paradigm research. Qualitative Inquiry, 16(1), 3-9.

Mellard, D. F., Deshler, D. D., \& Barth, A. (2004). LD identification: It's not simply a matter of building a better mousetrap. Learning Disability Quarterly, 27(4), 229-242.

Ontario Ministry of Education. (1982). Policy/Program Memorandum No. 8: The education of students with learning disabilities. Toronto, ON: Author.

Ontario Ministry of Education. (2001). Special education: A guide for educators. Toronto, ON: Author.

Ontario Ministry of Education. (2009). Closing the gaps for students with special needs in Ontario: Research trends and capacity building. Retrieved from http://www.edu.on.ca/eng/research/sped gap paper.pdf

Ontario Ministry of Education. (2012). An introduction to special education in Ontario. Retrieved from http://www.edu.gov.on.ca/eng/general/elemsec/speced/ontario.html

Ontario Psychological Association (OPA). (2008). OPA student assessment project: Summary of key results areas - critical findings. Retrieved from http://www.psych.on.ca/?id1=117

Phillips, R. (2010). Forgotten and ignored: Special education in First Nations schools in Canada. Canadian Journal of Educational Administration, 106, 1-26.

Philpott, D. F., Furey, E., \& Penney, S. C. (2010). Promoting leadership in the ongoing professional development of teachers: Responding to globalization and inclusion. Exceptionality Education International, 20(2), 38-54.

Portes, A. (1998). Social capital: Its origins and applications in modern sociology. Annual Review of Sociology, 24, 1-24.

Reay, D. (1998). Class work: Mothers' involvement in their children's primary schooling. London, UK: UCL Press.

Reid, D. K., \& Valle, J. W. (2004). The discursive practice of learning disability: Implications for instruction and parent-school relations. Journal of Learning Disabilities, 37(6), 466481.

Ryan, J. (2010). Establishing inclusion in a new school: The role of principal leadership. Exceptionality Education International, 20(2), 6-24.

Trainor, A. A. (2010a). Reexamining the promise of parent participation in special education: An analysis of cultural and social capital. Anthropology and Education, 41(3), 245-263.

Trainor, A. A. (2010b). Diverse approaches to parent advocacy during special education home- 
"Membership Has Its Privileges"

school interactions: Identification and use of cultural and social capital. Remedial and Special Education, 31(1), 34-47.

Worcester, J. A., Nesman, T. A., Raffaele Mendez, T. M., \& Keller, H. R. (2008). Giving voice to parents of young children with challenging behavior. Exceptional Children, 74(4), 509-525. 